\title{
Economic feasibility of calcium looping under uncertainty
}

\author{
Dawid P. Hanak*, Vasilije Manovic \\ Combustion and CCS Centre, Cranfield University, \\ Bedford, Bedfordshire, MK43 OAL, UK
}

Applied Energy, 2017, In Press

Corresponding author: ‘Dawid P. Hanak, d.p.hanak@cranfield.ac.uk 


\section{ABSTRACT}

An emerging calcium looping process has been shown to be a promising alternative to solvent scrubbing, which is regarded as the most mature $\mathrm{CO}_{2}$ capture technology. Its retrofits to coal-fired power plants have the potential to reduce both energy and economic penalties associated with the mature $\mathrm{CO}_{2}$ capture technologies. However, these conclusions have been made based on the deterministic outputs of the economic models that have not considered uncertainties in the model inputs. Therefore, this study incorporates a stochastic approach into the economic analysis of the retrofit of such emerging $\mathrm{CO}_{2}$ capture technology to the coal-fired power plant. The stochastic analysis revealed that levelised cost of electricity (LCOE) and specific total capital requirement were highly affected by the uncertainty in the input variables to the process and economic models. The most probable values for these key economic performance indicators were shown to fall between 75 and $115 € / \mathrm{MW}_{\text {elh, }}$

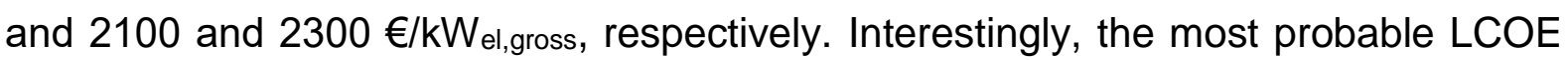
values for the coal-fired power plant will fall between 50 and $150 € / \mathrm{MW}_{\mathrm{el}} \mathrm{h}$. This indicated that the calcium looping retrofit scenario can become economically favoured, mainly due to the high economic penalties incurred by unabated coal-fired power plant associated with carbon tax. Importantly, the outputs of the stochastic economic assessment aligned well with the deterministic results reported in the literature. As the latter were generated using different sets of assumptions regarding the process and economic models, the stochastic approach to the economic assessment can minimise the impact of the model assumptions on estimates of the key economic parameters. Moreover, by indicating the probability of particular outputs, as well as ranking the model input variables according to their influence on the key economic performance, such analysis would allow making more insightful decisions regarding further funding 
and development of the calcium looping process. Finally, use of the stochastic approach in the economic feasibility assessment enables a more profound and reliable comparison of the different calcium looping retrofit configurations, as well as benchmarking different $\mathrm{CO}_{2}$ capture technologies.

Key Words: Uncertainty, probabilistic analysis, coal-fired power plant, process modelling and simulation, techno-economic analysis, calcium looping 


\section{INTRODUCTION}

To significantly reduce the risks and impacts associated with climate change, the mean temperature increase needs to be held well below $2^{\circ} \mathrm{C}$ and efforts to limit it to $1.5^{\circ} \mathrm{C}$ above pre-industrial levels need to be pursued [1]. Carbon capture and storage (CCS) technologies are expected to be essential for reducing the environmental impact of the power sector in the short- to mid-term [2], which is one of the major $\mathrm{CO}_{2}$ emitters due to a large share of coal-fired power plants in the global power generation fleet [3-5]. CCS has been shown to be the least cost-intensive option for decarbonisation of the power sector that would enable achieving the desired emission reduction levels by 2050 . This is primarily because of the high capital requirement of the alternative technologies, such as geothermal power plants and offshore wind farms $[2,6]$. Importantly, large-scale deployment of CCS is expected to reduce wholesale electricity prices in the UK by up to $15 \%$ by 2030 compared to a no-CCS scenario [6]. Also, lack of CCS in the power sector will require $40 \%$ higher capital cost to achieve more than $50 \%$ reduction of the global energy-related $\mathrm{CO}_{2}$ emissions by 2050 relative to 2009 (IEA $2^{\circ} \mathrm{C}$ scenario) [2].

Post-combustion $\mathrm{CO}_{2}$ capture technologies are regarded as the key class of CCS technologies for decarbonisation of the power sector, as they can be both easily retrofitted to the existing and integrated with the new-built coal-fired power plants $[7,8]$. Chemical solvent scrubbing using amine-based solvents, such as monoethanolamine (MEA), piperazine (PZ) or methyldiethanolamine (MDEA), is currently perceived as the most mature $\mathrm{CO}_{2}$ capture technology that will probably be a first choice technology for decarbonisation of coal-fired power plants [9-11]. However, despite the recent developments in chemical solvent scrubbing [12], retrofits of such technologies are predicted to reduce the net thermal efficiency of the entire system by $7-13 \%$ points 
$[10,13,14]$. A calcium looping process, which is based on the reversible carbonation reaction of lime with $\mathrm{CO}_{2}$, is considered as an emerging $\mathrm{CO}_{2}$ capture technology [15] and has already been demonstrated at a scale of $1.9 \mathrm{MW}_{\text {th }}[13]$. Integration of this process to the coal-fired power plant has been shown to impose a net efficiency penalty of $5-8 \%$ points $[13,16]$, which is lower compared to the figures reported for the mature $\mathrm{CO}_{2}$ capture technologies. As a result, it has been estimated that the cost of $\mathrm{CO}_{2}$ avoided corresponding to the calcium looping retrofits has a potential to be lower $\left(7-87.5 € / \mathrm{tCO}_{2}\right)[17-23]$ compared to that of the mature chemical solvent scrubbing $\left(35-75 € / \mathrm{tCO}_{2}\right)$ [24-27]. Therefore, calcium looping is perceived as an emerging $\mathrm{CO}_{2}$ capture technology that could reduce both energy and economic penalties associated with the mature $\mathrm{CO}_{2}$ capture technologies.

However, predictions of the economic performance indicators for retrofits of postcombustion $\mathrm{CO}_{2}$ capture technologies to coal-fired power plants have been only obtained using deterministic models. Although such approach can provide the point estimates of the economic performance indicators under any set of assumptions, these models do not consider the uncertainty in the input variables and are highly sensitive to selection of the particular set of assumptions. As the initial values for inputs to economic models, such as capital costs, fuel prices, carbon tax, and cost of $\mathrm{CO}_{2}$ transport and storage, can vary significantly depending on the considered economic environment [28], the deterministic nature of such model predictions does not provide a definitive representation of the actual system's economic performance. Importantly, around $40 \%$ of the mega-projects across different industries, which are usually defined as developments costing more than 1 billion USD, experience cost overruns [29]. This was also the case for the Kemper County and Boundary Dam projects that exceeded the initial cost estimation by a factor of 3 and 1.15 , respectively [30,31]. Importantly, 
the costs of the former project may further increase, as the unit is not yet operational. For this reason, the credibility of economic model prediction can be improved by considering the effect of uncertainty in the model inputs to generate the best- and the worst-case scenario estimates, as well as the probabilistic distributions of the economic model outputs.

An application of stochastic analysis to techno-economic assessment of the engineering systems has been shown to provide a more profound insight into operation and techno-economic performance of these systems [32-38]. As indicated above, the economic performance of the calcium looping retrofits has been only assessed using a deterministic approach, which does not account for the uncertainties in the model inputs. For this reason, this study incorporates the stochastic approach into the economic analysis of the retrofit of such emerging $\mathrm{CO}_{2}$ capture technology to the coal-fired power plant. This is achieved by combining a robust approximation model of the retrofitted system using a robust artificial neural network, which is developed from a finite number of deterministic simulations in Aspen Plus ${ }^{\circledR}$, and the economic model with the Monte Carlo simulation. It is expected that by considering the effect of uncertainties on the prediction of the key economic performance indicators, such as levelised cost of electricity (LCOE) and specific total capital requirement, this analysis would contribute to a more profound understanding of the system's economics, and thus its viability. Furthermore, an effect of variation in the key statistical parameters of the input variables, such as mean and extreme values, is analysed to identify the key input variables affecting the economic performance of the calcium looping process retrofit. 


\section{PROCESS MODEL DESCRIPTION}

\subsection{Supercritical coal-fired power plant}

The $580 \mathrm{MW}_{\text {el }}$ supercritical coal-fired power plant, which has a net thermal efficiency of $38.0 \% \mathrm{HHV}$, is used as a reference in this study. A process model of this unit has been previously developed in Aspen Plus ${ }^{\circledR}[39,40]$ based on, and validated with data presented in, the revised NETL report [41]. The considered coal-fired power plant comprises a power boiler, with $\mathrm{NO}_{x}$ and $\mathrm{SO}_{x}$ emission control equipment, as well as an electrostatic precipitator. In the power boiler, heat from the combustion of coal is utilised to raise high-pressure steam for the reheated regenerative steam cycle. The steam generator comprises primary, secondary, and reheat superheaters, as well as an economiser. The live (242.3 bar) and reheat steam (45.2 bar) raised in these sections leave the power boiler at a temperature of $593.3^{\circ} \mathrm{C}$, and are fed to the steam turbine section that comprises high- (HP), intermediate- (IP), and low-pressure (LP) extraction condensing steam turbines. To improve the efficiency of the steam cycle, a part of the steam from the turbine sections is drawn to feed the main feedwater heating train. This subsystem consists of five LP feedwater heaters, the last of which is called a deaerator and is a mixed feedwater heater, and three HP feedwater heaters.

\subsection{Calcium looping post-combustion $\mathrm{CO}_{2}$ capture plant}

A calcium looping process is considered in this study for decarbonisation of the conventional $580 \mathrm{MW}$ el coal-fired power plant. A process model for this unit has been developed in Aspen Plus ${ }^{\circledR}$ by Hanak et al. [42] and its prediction was found to be in good agreement with the experimental data at different flue gas loads. 


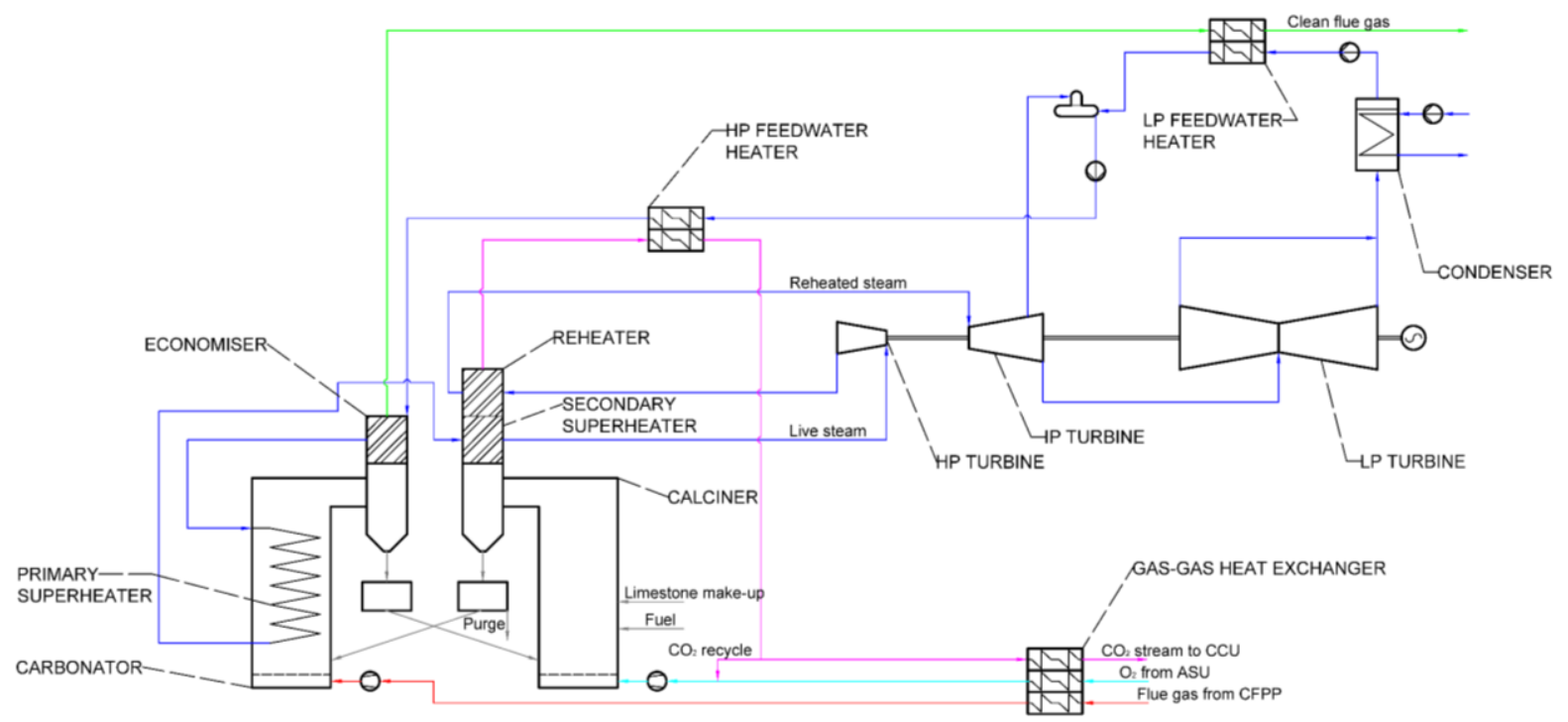

Figure 1: Process flow diagram of the calcium looping process for decarbonisation of the conventional $580 \mathrm{MW}_{\mathrm{el}}$ coal-fired power plant

The calcium looping process (Figure 1) comprises a carbonator, which is modelled as a stoichiometric reactor, and a calciner, which is modelled as a Gibbs reactor. To sustain the endothermic calcination reaction and ensure the high purity of $\mathrm{CO}_{2}$ leaving the calciner, an additional amount of coal is combusted in an $\mathrm{O}_{2} / \mathrm{CO}_{2}$ environment directly in this reactor. The coal decomposition is modelled using a yield reactor. The average sorbent conversion in the carbonator is estimated using the semi-empirical correlation shown in Eq. (1), which was derived by Rodríguez et al. [43], and the sorbent deactivation curve derived from experimental tests at the 1.7 $\mathrm{MW}_{\text {th }}$ La Pereda pilot plant [44]. In this correlation, the maximum average conversion of sorbent is a function of the carbonation $\left(f_{c a r b}\right)$ and calcination extent $\left(f_{c a l c}\right)$, sorbent characteristics $\left(a_{1}, a_{2}, f_{1}, f_{2}, b\right)$, fraction of never-calcined limestone in the system $\left(r_{0}\right)$, fresh limestone make-up $\left(F_{0}\right)$ and solid looping rate $\left(F_{R}\right)$. Moreover, the equilibrium partial pressures of $\mathrm{CO}_{2}$ in the gas streams leaving the carbonator and the calciner are determined using correlation by Baker [45], to account for the equilibrium limitations. 


$$
\mathrm{X}_{\text {ave }}=\left(F_{0}+F_{R} r_{0}\right) f_{\text {calc }}\left[\frac{a_{1} f_{1}^{2}}{F_{0}+F_{R} f_{\text {carb }} f_{\text {calc }}\left(1-f_{1}\right)}+\frac{a_{2} f_{2}^{2}}{F_{0}+F_{R} f_{\text {carb }} f_{\text {calc }}\left(1-f_{2}\right)}+\frac{b}{F_{0}}\right]
$$

The high-grade heat available in the carbonator and the process streams is utilised to raise high-pressure steam for the secondary steam cycle of similar operating characteristics to the one in the conventional $580 \mathrm{MW}_{\mathrm{el}}$ coal-fired power plant.

\section{STOCHASTIC ECONOMIC ASSESSMENT}

\subsection{Economic analysis methodology}

The economic performance of the calcium looping retrofit to the conventional $580 \mathrm{MWel}$ coal-fired power plant is assessed in terms of the levelised cost of electricity (LCOE) that is estimated using Eq. (2) $[19,20,46]$.

$$
L C O E=\frac{T C R \times F C F+F O M}{\dot{W}_{n e t} \times C F \times 24 \times 365}+V O M+\frac{S F C}{\eta_{t h}}
$$

This parameter correlates the thermodynamic performance indicators of the retrofitted system, such as net power output, net thermal efficiency, and capacity factor $(C F)$, with its economic performance indicators, such as total capital requirement $(T C R)$, variable (VOM) and fixed (FOM) operating and maintenance costs, specific fuel cost $(S F C)$, and the fixed charge factor $(F C F)$, which considers the system's lifetime and project discount rate. In this analysis, the total capital requirement includes the capital cost of both the reference coal-fired power plant and the calcium looping process. The capital cost of the reference coal-fired power plant is determined using the exponential method function [47]. Conversely, the capital cost of the calcium looping process $\left(C_{C a L}\right)$ is estimated using the correlation developed by Romano et al. [17] and represented by Eq. (3). This approach considers the capital cost for an oxy-fuel circulating-fluidised bed system as the reference capital cost $\left(C_{0}\right)$ [48], as well as allows taking into account the volume of the reactors $(V)$, the heat input in the calciner 
$\left(Q_{c a l c}\right)$, along with the corresponding scaling factors, and the fraction of the total cost of the calciner associated with the heat transfer surfaces $(\alpha)$.

$$
C_{\text {CaL }}=C_{0}\left[\alpha\left(\frac{Q_{\text {calc }}}{Q_{0, \text { calc }}}\right)^{S F, Q}+(1-\alpha)\left(\frac{V_{\text {calc }}}{V_{0, \text { calc }}}\right)^{S F, V}+(1-\alpha)\left(\frac{V_{\text {carb }}}{V_{0, \text { carb }}}\right)^{S F, V}\right]
$$

The fixed and variable operating and maintenance costs are expressed as a fraction of total capital cost, while operating costs associated with fuel and sorbent consumption, $\mathrm{CO}_{2}$ storage and transport, and $\mathrm{CO}_{2}$ emission are determined based on process simulation outputs and specific costs of these components.

\subsection{Stochastic assessment methodology}

The economic performance of the calcium looping process retrofit is dependent upon the assumptions in both the process and economic models. Although the deterministic models can provide a reliable prediction of the system's performance under any operating conditions, these models do not consider the stochasticity of the input variables that can be seen in the actual engineering systems and economic environments. Therefore, the deterministic economic assessment conducted according to the methodology presented in Section 3.1 does not provide a definitive representation of the actual system's performance that is often subjected to random fluctuations in the external and internal operating conditions [49]. To account for the uncertainty in the model input variables, the stochastic approach is adapted to the economic analysis methodology (Figure 2). 


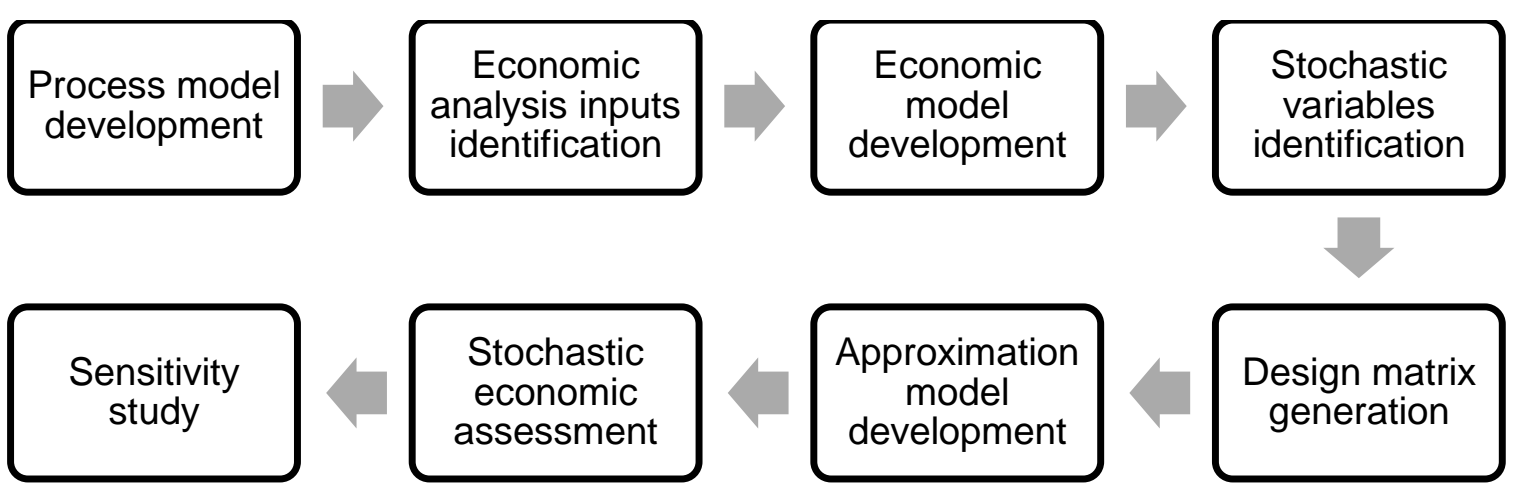

Figure 2: Overview of the stochastic economic assessment framework

The stochastic economic assessment framework employed in this study can be seen as a variation of the probabilistic performance assessment framework proposed by Hanak et al. [35,36], and comprises eight definitive stages. In the first stage, the process model has been developed in Aspen Plus ${ }^{\circledR}$ [42] and validated with the data available in the literature [44]. Next, the inputs from the process model to the economic analysis are identified, and then the economic model is built in MATLAB. Afterwards, the stochastic variables in both the process and economic models, as well as their statistical representation are identified. Then, similarly to the probabilistic performance assessment performed in the earlier studies by Hanak et al. $[35,36]$, the approximation model is developed based on the design matrix generated using the process model. Conversely to the process model, the economic model is much less computationally demanding, and thus it can be directly used in the stochastic economic assessment, even with a large number of iterations. In the next step, the stochastic economic assessment is conducted using the Monte Carlo simulations to generate the probability density curves for the key economic performance indicators including the LCOE and the specific total capital requirement. This is achieved by estimating the values of the key economic performance indicators using the input dataset that contains one million entries that have been randomly generated according to the assumed distributions of the input variables. Finally, the sensitivity study is performed 
to assess the effect of the key statistic parameters of the stochastic variables, which include the mean value for the normally distributed variables and the extreme values for the uniformly distributed variables, on the key economic performance indicators.

\subsection{Identification of stochastic variables}

Having analysed both the process and economic models, the stochastic input variables have been categorised into process, scale and size, and economic variables (Table 1). First, the thermodynamic performance of the calcium looping retrofit is mainly sensitive to four process variables including the relative fresh sorbent make-up rate, $\mathrm{O}_{2}$ content in the calciner inlet gas stream, $\mathrm{O}_{2}$ content in the calciner outlet gas stream, which determines the excess $\mathrm{O}_{2}$ in the calciner, and the $\mathrm{CO}_{2}$ capture level in the carbonator $[18,23,42,50-52]$. These input variables are assumed to be normally distributed with the statistic parameters determined from the literature $[32,34,53,54]$.

Secondly, the size of the equipment in the calcium looping retrofit scenario is dependent upon selection of the scaling factors and operating conditions. It is assumed that the scaling factors are normally distributed with the coefficient of variation of $5 \%[32,34]$. Conversely, the superficial velocity in, and the height-todiameter ratio of, the fluidised beds are assumed to be uniformly distributed, as the optimum specifications have not been yet identified. Therefore, the minimum and maximum values are identified from the literature $[13,55,56]$.

Finally, the economic performance of the calcium looping retrofit scenario is dependent upon the economic variables related to the operating costs, reference specific capital costs, and the project characteristics. Most of these variables are assumed to be normally distributed [32,34], with exception of the carbon tax and the specific cost of $\mathrm{CO}_{2}$ transport and storage. As the carbon tax may vary between 10- 
$150 € / \mathrm{tCO}_{2}[57,58]$ and specific cost of $\mathrm{CO}_{2}$ transport and storage/utilisation may vary between $-15-40 € / \mathrm{tCO}_{2}[23,24]$, depending on whether $\mathrm{CO}_{2}$ is stored or utilised, for example, for enhanced oil recovery, the mean value for these variables is uncertain. Therefore, these variables are assumed to be uniformly distributed.

Table 1: Stochastic variables and their distribution

\begin{tabular}{|c|c|c|c|}
\hline Variable & Distribution & Nominal value & Variation $^{*}$ \\
\hline \multicolumn{4}{|l|}{ Process variables } \\
\hline Relative fresh sorbent make-up rate (mole basis) $[53,54]$ & Normal & 0.05 & $20 \%$ \\
\hline $\mathrm{O}_{2}$ content in calciner inlet gas stream (mole basis) $[32,34]$ & Normal & 0.3 & $5 \%$ \\
\hline $\mathrm{O}_{2}$ content in calciner outlet gas stream (mole basis) $[32,34]$ & Normal & 0.025 & $2.5 \%$ \\
\hline $\mathrm{CO}_{2}$ capture level (-) $[32,34]$ & Normal & 0.9 & $2.5 \%$ \\
\hline \multicolumn{4}{|l|}{ Scale and size variables } \\
\hline Scaling factor of coal-fired power plant (-) $[32,34]$ & Normal & 0.67 & $5 \%$ \\
\hline Scaling factor for the heat transfer surfaces (-) $[32,34]$ & Normal & 0.85 & $5 \%$ \\
\hline Scaling factor for the heat rate in the calciner $(-)[32,34]$ & Normal & 0.9 & $5 \%$ \\
\hline Scaling factor for volume of the reactors $(-)[32,34]$ & Normal & 0.67 & $5 \%$ \\
\hline Superficial velocity $(\mathrm{m} / \mathrm{s})[13,55]$ & Uniform & 5 & $2-14$ \\
\hline Height-to-diameter ratio (-) [56] & Uniform & 3 & $2-4$ \\
\hline \multicolumn{4}{|l|}{ Economic variables } \\
\hline Variable operating and maintenance cost rate (\%/year) $[32,34]$ & Normal & 2 & $10 \%$ \\
\hline Fixed operating and maintenance cost rate $(\% /$ year $)[32,34]$ & Normal & 1 & $10 \%$ \\
\hline Carbon tax (€/tonne) $[57,58]$ & Uniform & 30 & $10-150$ \\
\hline Specific cost of $\mathrm{CO}_{2}$ transport and storage (€/tonne) $[23,24,59,60]$ & Uniform & 7 & $-15-40$ \\
\hline Specific cost of sorbent $(€ /$ tonne $)[32,34]$ & Normal & 6 & $25 \%$ \\
\hline Specific cost of coal $(€ /$ GJ) $[32,34]$ & Normal & 1.5 & $25 \%$ \\
\hline Project discount rate $(\%)[32,34]$ & Normal & 8.78 & $10 \%$ \\
\hline Capacity factor $(\%)[32,34]$ & Normal & 80 & $7 \%$ \\
\hline Reference specific capital cost of coal-fired power plant $(€ / \mathrm{kW})[32,34]$ & Normal & 1100 & $10 \%$ \\
\hline Reference specific capital cost of calcium looping process $(€ / \mathrm{kW})[32,34]$ & Normal & 1252.3 & $10 \%$ \\
\hline
\end{tabular}

\subsection{Stochastic response surface approximation model using artificial neural network}

The process models developed in Aspen Plus ${ }^{\circledR}$ cannot be directly used to provide the process input to the stochastic economic assessment, because a large number of iterations required in the stochastic analysis would require a high computational demand. For this reason, this study utilises the deterministic process model described in Section 2 to generate the design matrix that is, in turn, used to develop the robust approximation model. Such model will link the process input variables to the process models with the process output variables, the latter of which will be considered as input 
variables to the economic model. The design matrix ${ }^{*}$ used in this study comprises 32 entries of the process input variables required by the economic analysis resulting from the following variation of the stochastic process variables:

- Relative make-up rate was varied between 0.02 and 0.1 ;

- $\mathrm{O}_{2}$ content in the calciner inlet gas stream was varied between 0.3 and 0.95 ;

- $\mathrm{O}_{2}$ content in the calciner outlet gas stream was varied between 0.005 and 0.045 ;

- $\mathrm{CO}_{2}$ capture level in the carbonator was varied between 0.7 and 0.9 .

The earlier studies by Hanak et al. $[35,36]$ utilised the generic quadratic multi-variable polynomial (MVR) model shown in Eq. (4) as the approximation model.

$$
\tilde{g}(u)=a+\sum_{i=1}^{n} b_{i} \cdot u_{i}+\sum_{i=1}^{n} c_{i} \cdot u_{i}^{2}
$$

However, such an approximation model would need to be derived for each of the process output variables that are required in the economic model. Moreover, the quadratic MVR may struggle to accurately represent nonlinear characteristics of the process model [61]. For this reason, this study utilises the artificial neural network (ANN) to accurately link the process inputs to the process model with the process inputs to the economic model.

*The design matrix is provided in the Supplementary Information. 


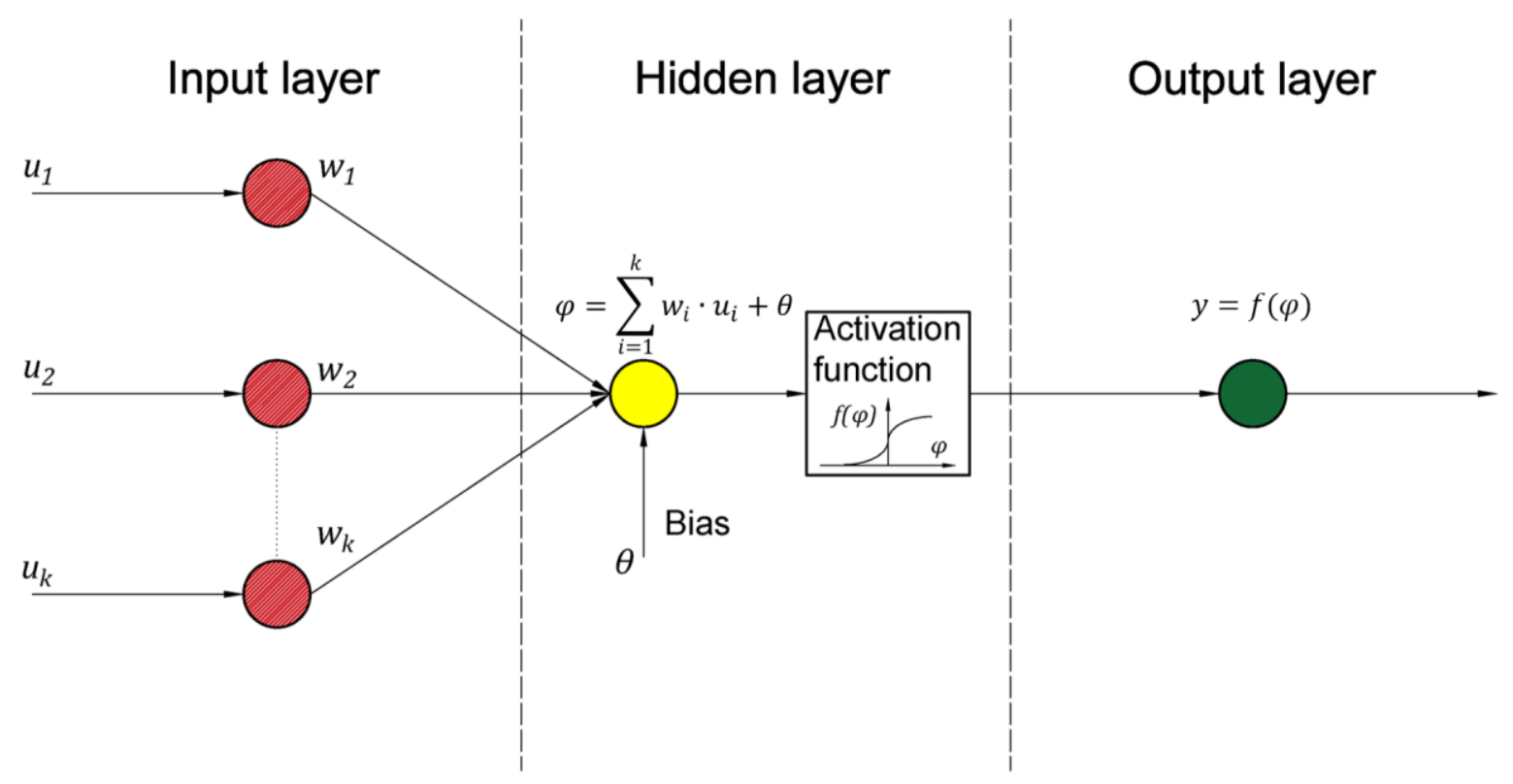

Figure 3: Nonlinear model of a sigmoid neuron (Adapted with permission from Oko et al. [62] and Kalogirou [63]. Copyright 2017, Elsevier)

The ANN is inspired by the structure of biological neural networks and the process they utilise to solve problems [62]. As opposed to the conventional approximation models, ANN learns the relations between the inputs and outputs by training [64]. It is also known to be able to reliably represent multiple outputs considering multiple inputs [63], even if the system's behaviour is highly nonlinear [64]. The most common structure of the ANN is shown in Figure 3 and comprises an input layer, one hidden layer with sigmoid neurons, and an output layer with linear neurons $[64,65]$. The input to each neuron can be the network input from the input layer, the output of the neuron in the previous layer, and an externally applied bias [62]. The output of each neuron is the function of the weighted sum of the neuron inputs, with the hyperbolic tangent sigmoid transfer function shown in Eq. (5) used in the hidden layer and the linear function shown in Eq. (6) used in the output layer. The weights and bias are determined in the training process by minimising error between the ANN outputs and the design matrix. 


$$
\begin{aligned}
& f(\varphi)=\frac{2}{1+\mathrm{e}^{-2\left(\sum_{i=1}^{k} w_{i} \cdot u_{i}+\theta\right)}-1} \\
& f(\varphi)=\sum_{i=1}^{k} w_{i} \cdot u_{i}+\theta
\end{aligned}
$$

Using the MATLAB Neural Network Fitting toolbox, a two-layer feed-forward ANN with ten sigmoid hidden neurons and linear output neurons (Figure 4) is developed to map the design matrix generated using the process model. To ensure an accurate prediction by the ANN, the data in the design matrix were randomly divided between training $(70 \%)$, validation (15\%) and testing (15\%) samples. Moreover, the number of the hidden neurons has been selected to be higher than the number of the ANN output parameters. In the considered scenario of the calcium looping process retrofit, eight process variables are required to conduct the economic analysis as presented in Figure 4. Therefore, ten sigmoid hidden neurons are considered. The weights and bias in the ANN have been determined using the Levenberg-Marquardt backpropagation algorithm with Bayesian regularisation, as it is expected to result in good representation of nonlinear and small datasets.

To ensure that the ANN accurately predicts the thermodynamic performance of the calcium looping retrofit, its performance is benchmarked against the data matrix generated using the process model developed in Aspen Plus ${ }^{\circledR}$ and compared to the predictions of the approximation model based on the generic quadratic MVR. With four input and eight output variables, there are thirty-two directional outputs to be considered. For this reason, a representative sample was selected and is evaluated in this section (Figure 5), while the information on all directional outputs is presented along with the design matrix in the Supplementary Information. Analysis of the selected directional outputs (Figure 5) revealed that the ANN used in this study is 
capable of mapping the thermodynamic performance of the calcium looping retrofit accurately, despite its nonlinear characteristic. Importantly, the ANN was shown to outperform the generic quadratic MVR that tends to perform well only in representing linear and slightly nonlinear outputs. In strongly nonlinear cases, however, the latter approximation model tends to predict the general trends, but not the actual values. Therefore, the ANN is deemed to represent the design matrix more accurately and is used in the stochastic economic assessment.

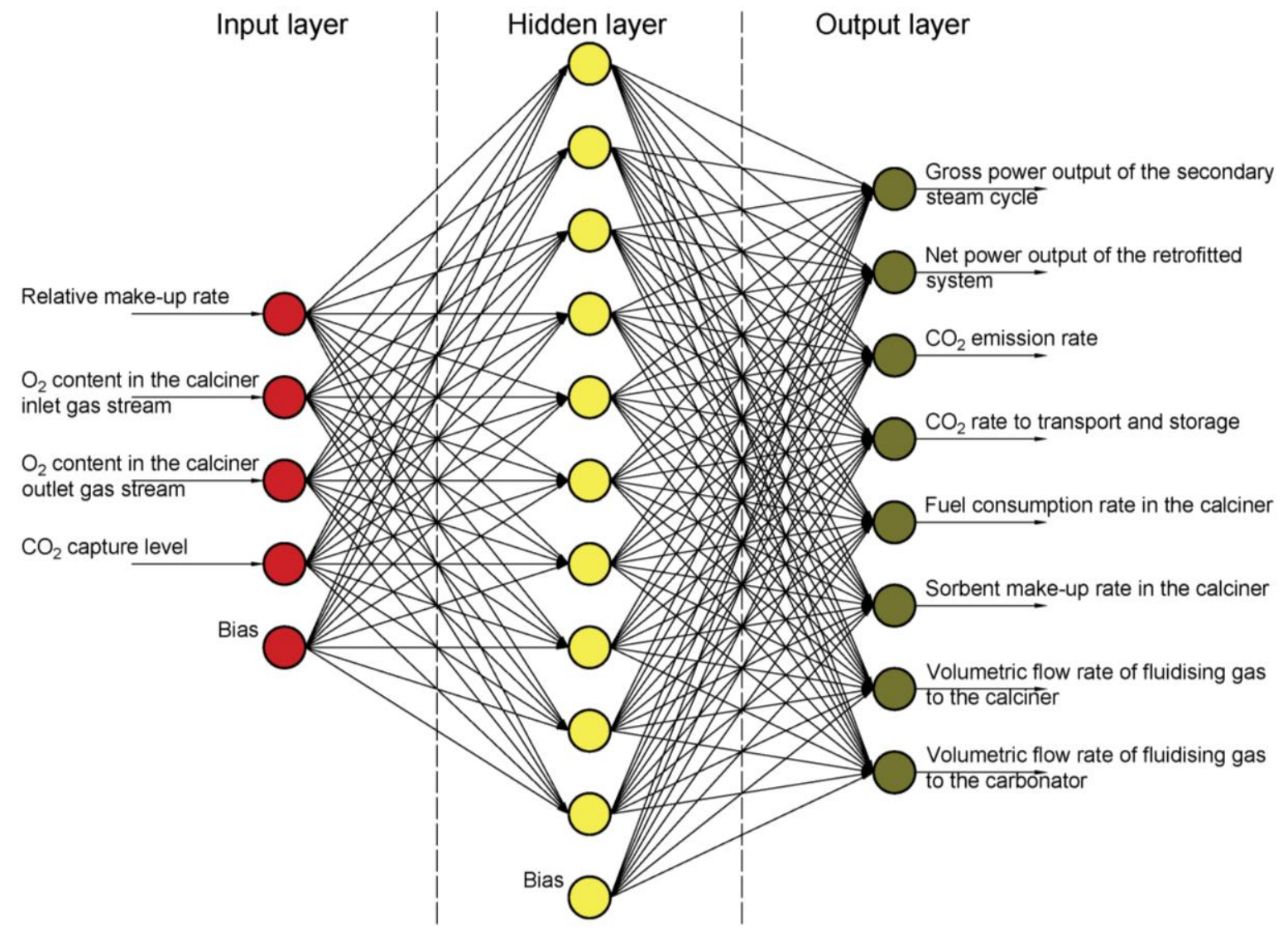

Figure 4: Structure of the artificial neural network used to map the thermodynamic performance of the calcium looping process retrofit 


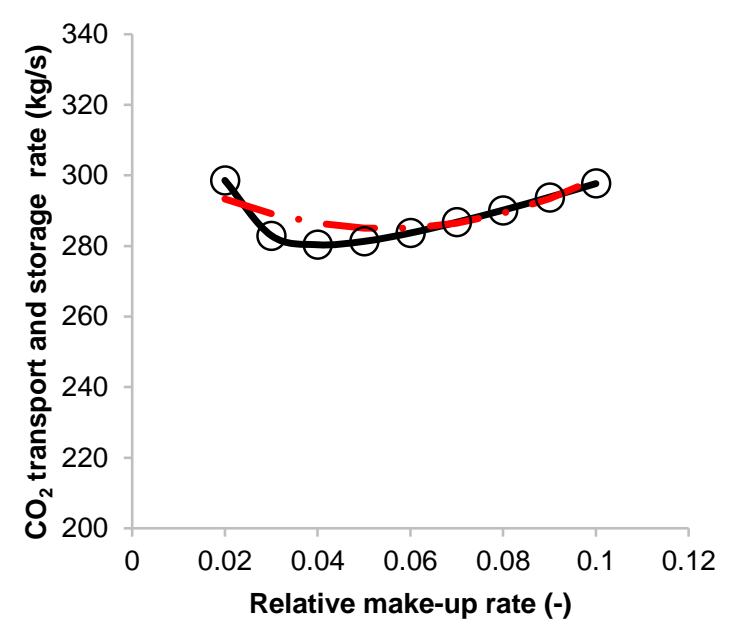

○ Aspen Plus $\longrightarrow$ ANN $\longrightarrow$ MVR

a)

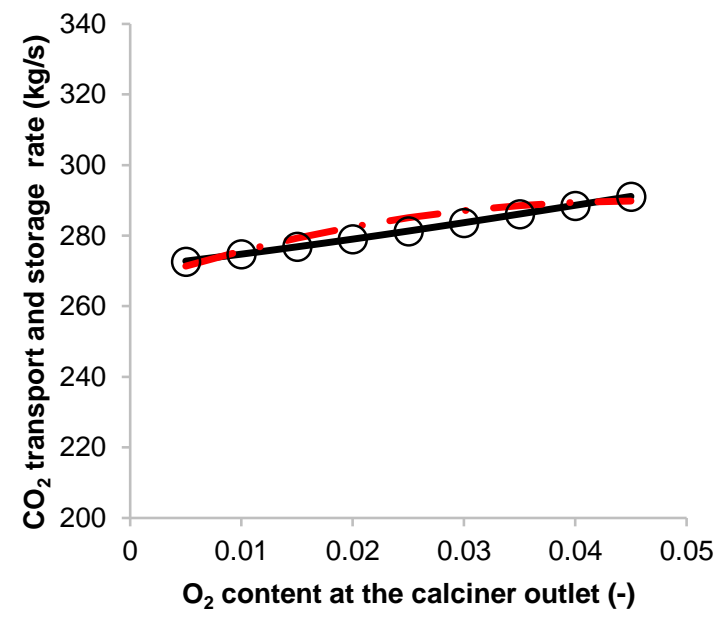

$\circ$ Aspen Plus $\longrightarrow$ ANN - MVR

c)

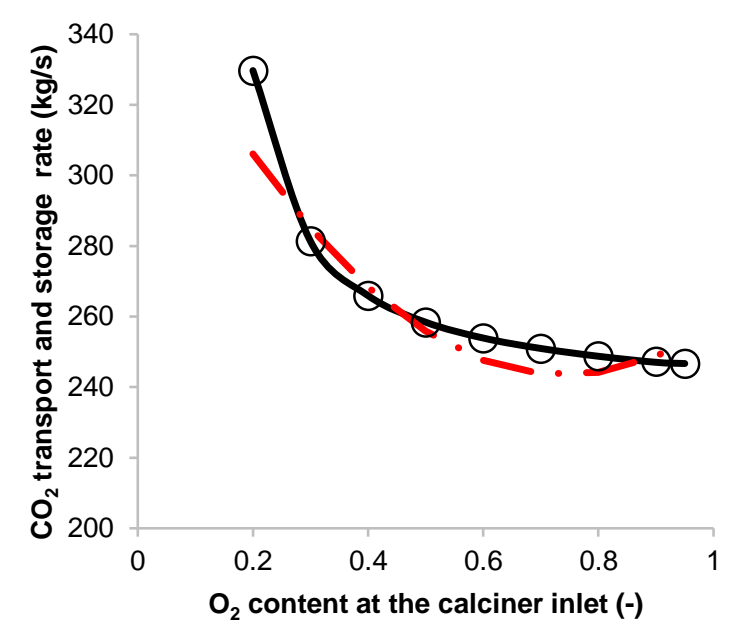

○ Aspen Plus $\longrightarrow$ ANN $\longrightarrow$ MVR

b)

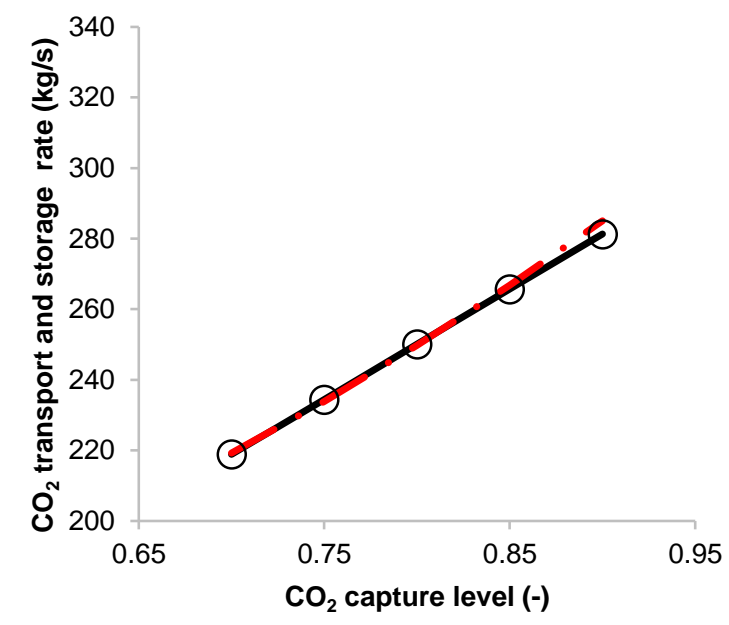

- Aspen Plus $\longrightarrow$ ANN $\longrightarrow$ MVR

d)

Figure 5: Comparison of the directional outputs for $\mathrm{CO}_{2}$ transport and storage rate generated using artificial neural network (ANN), quadratic multi-variable polynomial (MVR) and Aspen Plus ${ }^{\circledR}$

\section{ECONOMIC PERFORMANCE ASSESSMENT}

\subsection{Effect of uncertainty on levelised cost of electricity}

The LCOE is considered as one of the key economic performance indicators for the power generation systems, including CCS retrofits, as it indicates the unit cost of electricity that is required to cover the lifetime costs of the entire system. The effect of uncertainty on the LCOE of the reference coal-fired power plant (reference scenario) 
and the calcium retrofit scenario (retrofit scenario) is presented in Figure 6 . The analysis has revealed that the statistical distribution of the LCOE is close to uniform and normal distribution in the reference and retrofit scenario, respectively. In both cases, elongated regions of the highest probability density can be observed, but it is considerably longer in the former case; hence, the distribution of the LCOE in the reference scenario is close to uniform distribution. This is caused by the fact that the uniform distribution has been assigned to some of the stochastic variables, which in the reference scenario have a high influence on the LCOE. It has been also estimated that the mean value of the LCOE in the reference scenario is $95.6 € / M \mathrm{Mel}_{\text {el }}$ with the figures for the $5^{\text {th }}$ and $95^{\text {th }}$ percentile estimated to be 41.6 and $149.6 € / \mathrm{MW}_{\text {elh, }}$ respectively. Interestingly, the mean value of the LCOE associated with the calcium looping process retrofit has been estimated to be lower (92.5€/MWelh), with the figures for the $5^{\text {th }}$ and $95^{\text {th }}$ percentile estimated to be 59.0 and $126.2 € / \mathrm{MW}_{\text {elh }}$, respectively. Lower figures for the mean value and $95^{\text {th }}$ percentile of the LCOE in the latter case indicate that even in the worst-case scenario, the calcium looping retrofit can become more feasible than the reference coal-fired power plant, especially in light of expected increase of the carbon tax. Importantly, the distribution of the LCOE in the retrofit scenario aligns well with the deterministic values for the LCOE from a range of cases reported in previous studies [17-23], all of which have been overlaid onto the probability density curve in Figure 6. Importantly, these deterministic values can be mostly classified as the best-case (25.8-54.3 €/MW elh) [18-20] and probable-case (68.4-82.5 €/MWelh) $[17,19-22]$ scenarios, while a limited number of studies represent the worst-case scenario (116.7 €/MW elh) [23]. The stochastic economic assessment indicated that the most probable figure for the LCOE for the considered calcium looping process retrofit falls between 75 and $115 € / M W_{\text {elh }}$. 


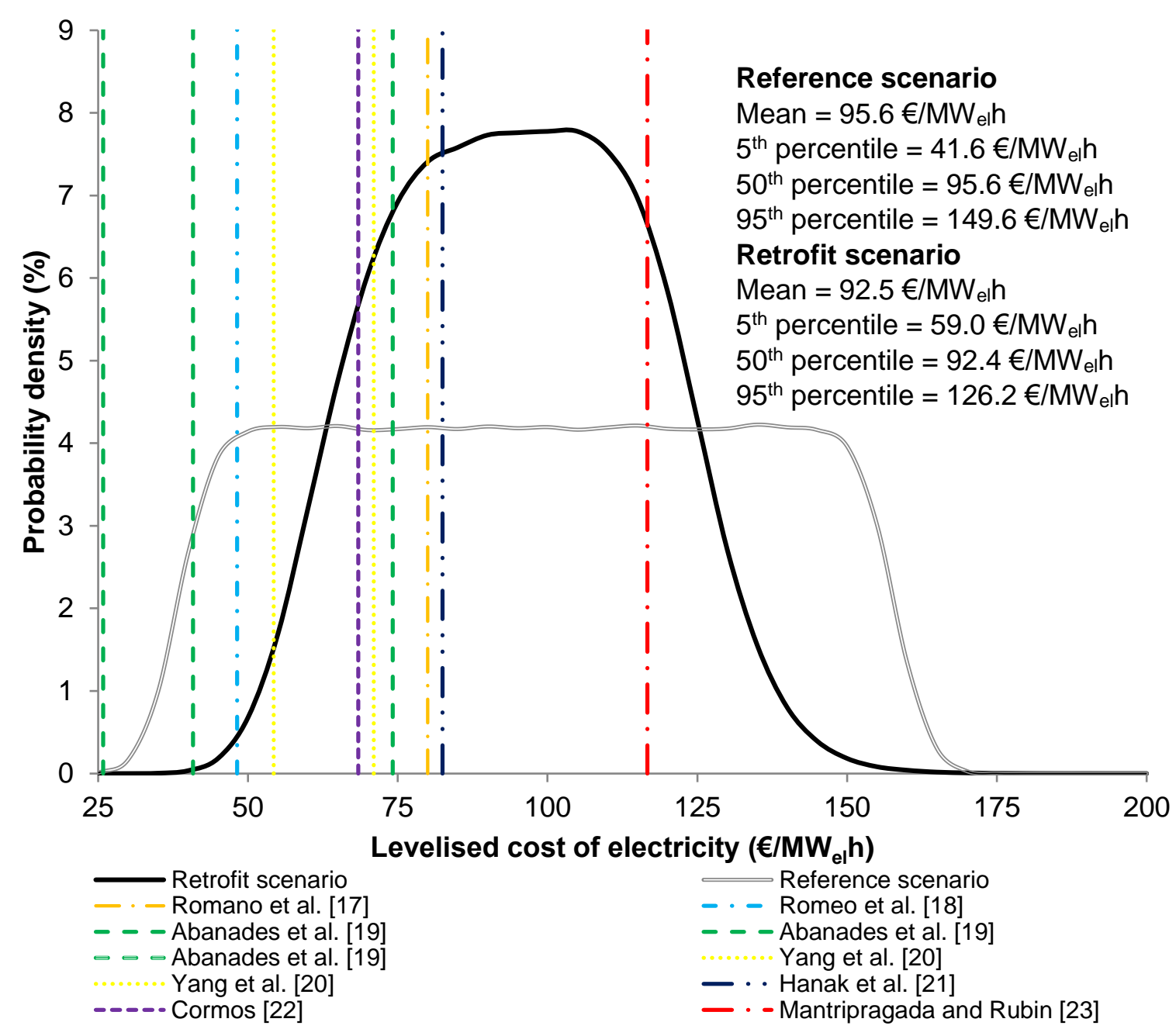

Figure 6: Effect of uncertainty on the levelised cost of electricity 
Carbon tax (maximum value)

Capacity factor

Reference specific capital cost of coal-fired power plant

Coal price

Project discount rate

Variable operating and maintenance cost rate

Scaling factor of coal-fired power plant

$$
-8
$$

$-6$
Fixed cost rate

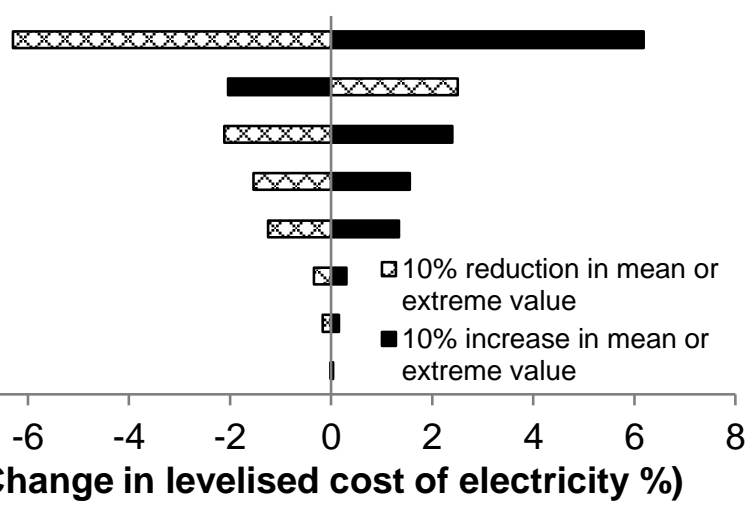

a)

Capacity factor

$\mathrm{CO}_{2}$ capture rate

Reference specific capital cost of calcium looping

$\mathrm{O}_{2}$ content in the calciner inlet gas stream

Scaling factor for heat rate in the calciner

Project discount rate

Cost for $\mathrm{CO}_{2}$ transport and storage (maximum value)

Coal price

Reference specific capital cost of coal-fired power plant

Scaling factor for the heat transfer surfaces

Variable operating and maintenance cost rate

Cost for $\mathrm{CO}_{2}$ transport and storage (minimum value)

Scaling factor for volume of the fluidised bed

Fluidised bed superficial velocity (maximum value)

Fixed cost rate

Carbon tax (maximum value)

$\mathrm{O}_{2}$ content in the calciner outlet gas stream

Fluidised bed height to diameter ratio (maximum value)

Fluidised bed superficial velocity (minimum value)

Fluidised bed height to diameter ratio (minimum value)

Sorbent cost

Relative fresh sorbent make-up rate Scaling factor of coal-fired power plant

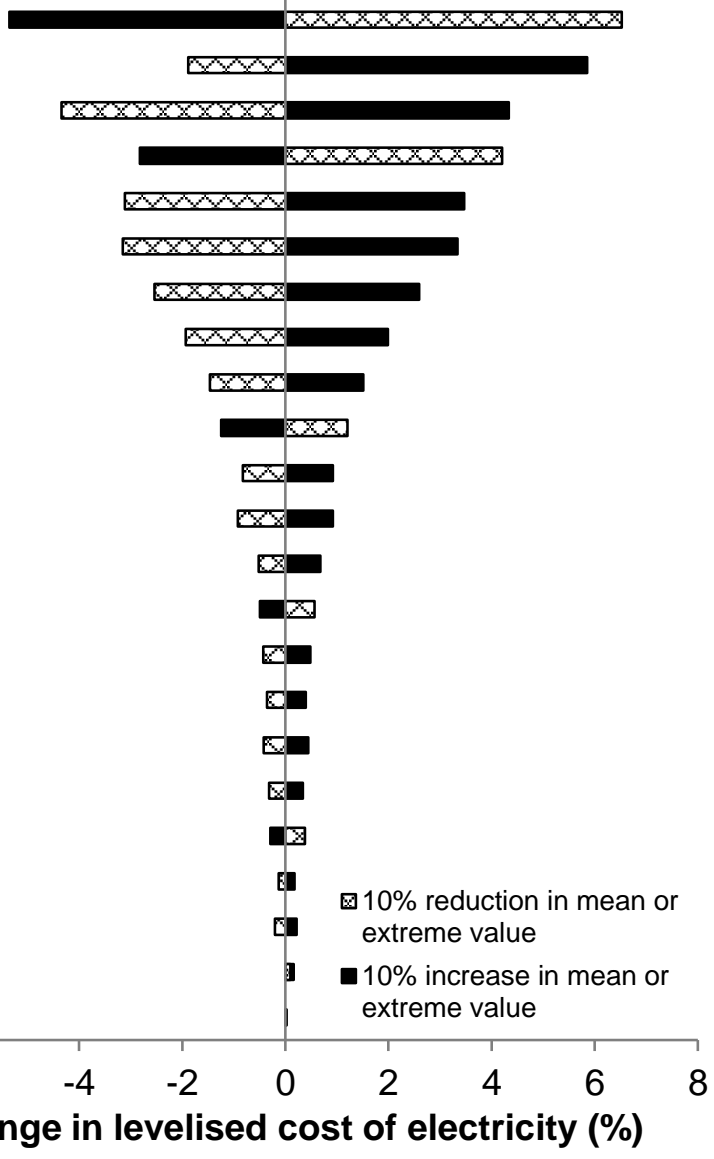

b)

Figure 7: Effect of key statistic parameters sensitivity on the levelised cost of electricity in the a) reference and $b$ ) retrofit scenario

The sensitivity analysis performed on the key statistic parameters of the selected stochastic variables (Figure 7a) has indicated that the LCOE in the reference scenario is mostly sensitive to the carbon tax. Change of $\pm 10 \%$ in the maximum value of this parameter resulted in the LCOE varying between $-5.4 \%$ and $6.5 \%$. This is due to the 
economic penalties that can be associated with $\mathrm{CO}_{2}$ emissions and that increase with carbon tax. Importantly, the LCOE varied by $\pm 2 \%$ on change in capacity factor, reference specific capital cost of coal-fired power plant, coal price and project discount rate, but was found to be rather insensitive to variable and fixed cost rates, as well as the scaling factor of coal-fired power plant. Furthermore, the analysis (Figure 7b) has indicated that the LCOE in the retrofit scenario is equally sensitive to the economic, process, as well as scale and size variables. In contrast to the reference scenario, it has been observed that the capacity factor had the highest influence on the LCOE, as it varied by $-5.3 \%$ and $6.5 \%$ on $10 \%$ change in the mean value of the capacity factor. This can be directly associated to the amount of electricity generated over the project lifetime, and thus low capacity factor would result in low amount of electricity generated and high LCOE. Furthermore, a $10 \%$ increase in the mean value of the $\mathrm{CO}_{2}$ capture level in the carbonator resulted in $5.9 \%$ increase in the LCOE, which can be associated with the extra capacity of the calcium looping process. It needs to be stressed that such high $\mathrm{CO}_{2}$ capture level (>95\%) may not be achievable under the assumed operating conditions in the carbonator due to the equilibrium limits. Importantly, a $10 \%$ decrease in the mean value of the $\mathrm{CO}_{2}$ capture level in the carbonator resulted in only $1.9 \%$ reduction in the LCOE. This can be associated with more $\mathrm{CO}_{2}$ being emitted into the atmosphere, and thus the benefit of the reduced capital cost requirement is diminished by an additional expenditure on carbon tax, which increases as the $\mathrm{CO}_{2}$ capture level decreases. Interestingly, a $2.9 \%$ reduction in the LCOE can be achieved on a $10 \%$ increase in the mean value of the $\mathrm{O}_{2}$ content in the calciner inlet gas stream. This indicates that operating the calciner with reduced recycle of the $\mathrm{CO}_{2}$ stream may improve the economic performance of the entire system, providing that no hot-spots occur in the calciner causing excessive degradation of the sorbent. Moreover, both the 
reference specific capital cost of the calcium looping process and the scaling factor for the heat rate in the calciner were found to have a significant effect on the LCOE, as a $10 \%$ increase in their mean values resulted in a 4.4 and $3.5 \%$ increase in the LCOE, respectively. This can be directly associated with an increase in the total capital requirement. Finally, the LCOE was shown to vary by more than $\pm 1 \%$ on variation in the mean values of the economic variables, such as reference specific capital cost of coal-fired power plant, project discount rate, cost of $\mathrm{CO}_{2}$ transport and storage, as well as the maximum value of the coal price. The variations in the remaining stochastic variables, including the carbon tax, have been shown to have a minor or negligible effect on the LCOE.

\subsection{Effect of uncertainty on specific total capital requirement}

In addition to the LCOE, the specific total capital requirement, which indicates the unit capacity cost, can be considered as an important parameter in assessment of the economic feasibility of the CCS retrofits. The stochastic analysis has shown that, opposed to the LCOE, the specific total capital requirement is a slightly positivelyskewed normal distribution (Figure 8a). This is primarily caused by the exponential correlation between the equipment cost and the stochastic variables, and the fact that the stochastic variables with uniform distribution do not have a significant influence on the specific total capital requirement (Figure 8b). The analysis has shown that the mean value of the specific total capital requirement is $2217.9 € / \mathrm{kW}$ el,gross and it ranges between 1808.6 ( $5^{\text {th }}$ percentile) and $2776.9 € / \mathrm{kWel,gross}\left(95^{\text {th }}\right.$ percentile). Importantly, the $50^{\text {th }}$ percentile value was estimated to be $2176.4 € / \mathrm{kW}$ el,gross, which, as opposed to the LCOE, differs from the mean value considerably, and thus, it represents the value of the specific total capital requirement with the highest probability. Comparing the results of the stochastic economic analysis with those in the literature, it can be noted 
that most of the studies used the best-case estimate of the specific total capital

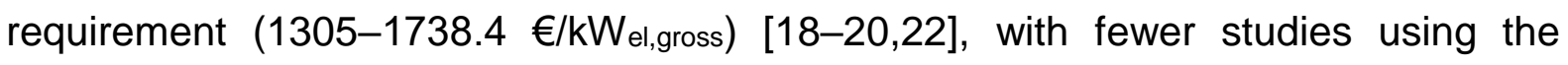
probable-case estimate (1812.5-2097.3 €/kWel,gross) [19-21]. Importantly, a limited number of studies considered the worst-case estimate (3723.9 $€ / \mathrm{kW}$ el,gross) [23] that is more than double the $5^{\text {th }}$ percentile value, as well as 1.7 and 1.3 times higher than the $50^{\text {th }}$ and $95^{\text {th }}$ percentile values, respectively, estimated in this study. As indicated in Section 4.1, the capital requirement has a significant effect on the estimation of the LCOE. As a result of considering the worst-case estimate of the specific total capital requirement, the key economic performance indicators of the calcium looping retrofit are higher compared to the mean values estimated in this study using the stochastic approach and the deterministic values reported in the literature that were based on best- and probable-case estimates. It needs to be stressed, however, that although the stochastic economic assessment indicated that the most probable figure for the total capital requirement of the calcium looping retrofit falls between 2100 and 2300 $€ / \mathrm{kW}_{\text {el,gross, }}$ the probability that it would be higher than $3500 € / \mathrm{kW}_{\text {el,gross }}$ has been estimated to be $0.2 \%$. 


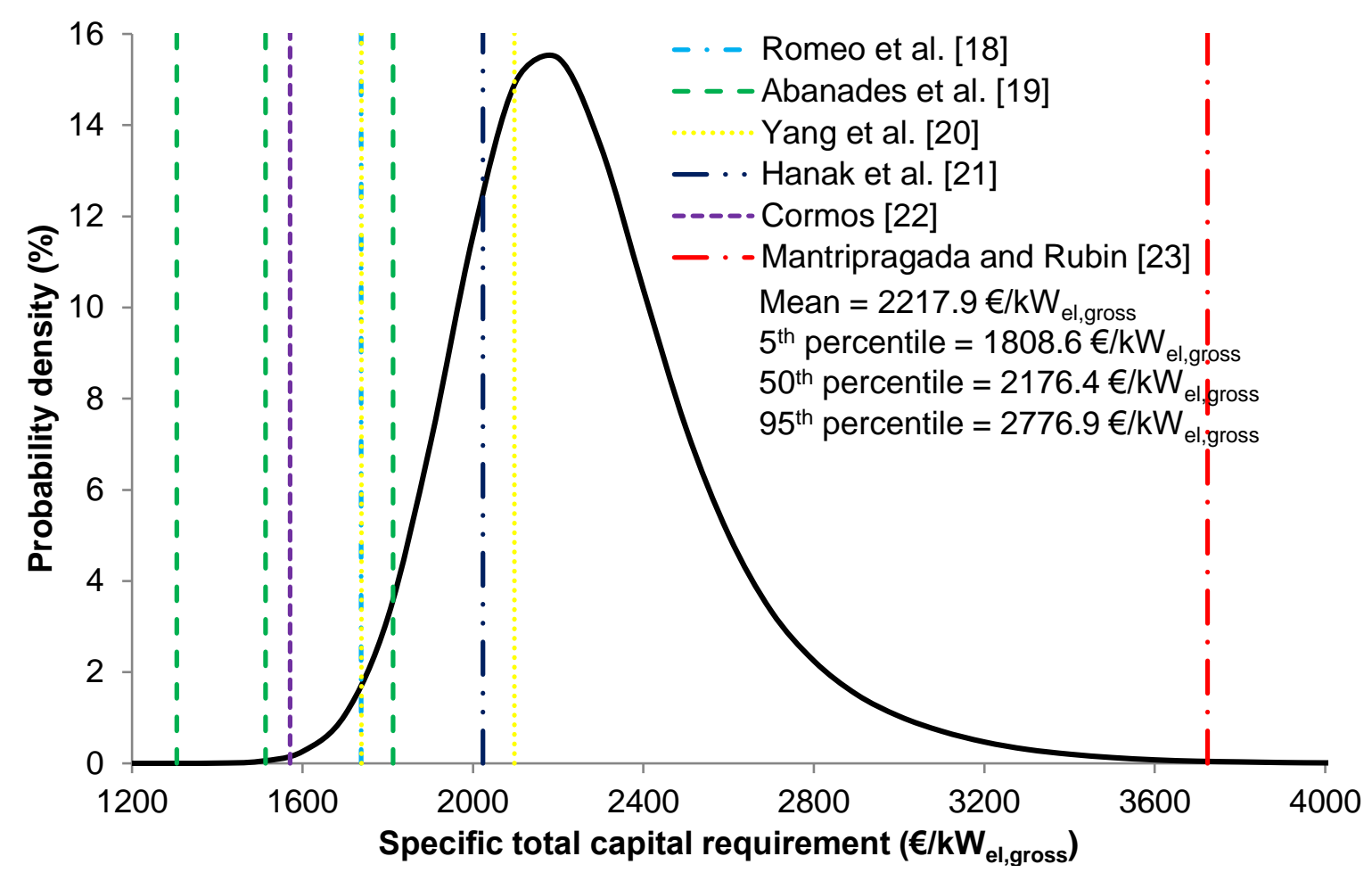

a)

$\mathrm{CO}_{2}$ capture rate

Reference specific capital cost of calcium looping

$\mathrm{O}_{2}$ content in the calciner inlet gas stream

Scaling factor for heat rate in the calciner

Reference specific capital cost of coal-fired power plant

Fluidised bed superficial velocity (maximum value)

Relative fresh sorbent make-up rate

Scaling factor for the heat transfer surfaces

Scaling factor for volume of the fluidised bed

Fluidised bed height to diameter ratio (maximum value)

$\mathrm{O}_{2}$ content in the calciner outlet gas stream

Fluidised bed height to diameter ratio (minimum value)

Fluidised bed superficial velocity (minimum value)

Variable operating and maintenance cost rate

Capacity factor

Project discount rate

Sorbent cost

Coal price

Scaling factor of coal-fired power plant

Cost for $\mathrm{CO}_{2}$ transport and storage (minimum value)

Cost for $\mathrm{CO}_{2}$ transport and storage (maximum value)

Fixed cost rate

Carbon tax (maximum value)

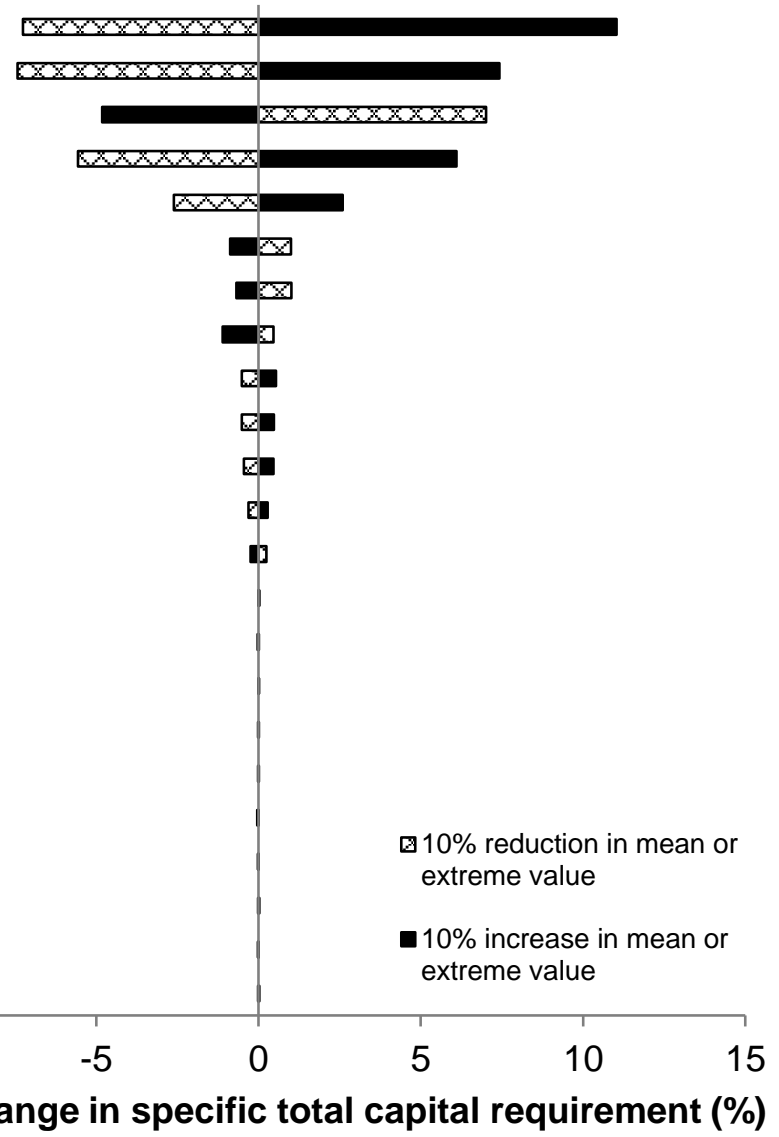

b)

Figure 8: Effect of a) uncertainty and b) key statistic parameters sensitivity on the specific total capital cost requirement 
As opposed to the LCOE, the sensitivity analysis performed on the key statistic parameters of the selected stochastic variables (Figure 8b) showed that the specific total capital requirement is mainly sensitive to the process variables, such as $\mathrm{CO}_{2}$ capture level and the $\mathrm{O}_{2}$ content in the calciner inlet gas stream. On the one hand, the largest variation was observed on a $10 \%$ variation in the mean value of the $\mathrm{CO}_{2}$ capture level in the carbonator, as it was shown to result in the specific total capital requirement varying by -7.2 to $11.1 \%$. This is directly related to the size of the equipment required to achieve desired $\mathrm{CO}_{2}$ capture level. On the other hand, a $10 \%$ increase in the mean value of the $\mathrm{O}_{2}$ content in the calciner inlet gas stream was found to reduce the specific total capital requirement by $4.8 \%$. This arises from smaller size of the calciner due to reduced requirement for the $\mathrm{CO}_{2}$ recycle. It is important to point out that the main economic variables that affect the specific total capital requirement are the reference specific capital cost of the calcium looping process and the coal-fired power plant. The variation in the remaining stochastic variables have been shown to have a minor or negligible effect on the specific total capital requirement.

\subsection{Contribution to deployment of calcium looping process}

The economic assessment using the stochastic approach employed in this study allowed predicting the envelopes for the system's key economic performance indicators under uncertain process and economic input conditions. The outcome of such analysis identified the economic performance of the considered system that can be classified as the worst-, probable-, and the best-case scenarios corresponding to $95^{\text {th }}, 50^{\text {th }}$, and $5^{\text {th }}$ percentile, respectively. Furthermore, by considering a large number of the stochastic variables, both from the process and the economic model, the stochastic economic assessment can rank the model input variables according to their influence on the key economic performance indicators. Therefore, by considering the 
uncertainty in the process and economic model inputs, the stochastic economic assessment will provide the most probable estimate for the key economic performance indicators and thus will provide a valuable input to the investment decision-making process.

The results of the stochastic economic analysis presented in Section 4 are in agreement with the wide range of the deterministic outcomes from the studies reported in the literature. It needs to be stressed, however, that the studies reported in the literature were conducted with different sets of assumptions regarding the thermodynamics of the reference coal-fired power plant and the operating conditions of the calcium looping process, as well as the economic assumptions. The fact that these deterministic results align well with the outcomes of the stochastic economic assessment conducted in this study implies that such approach can alleviate the impact of the assumptions on the economic estimates, and thus, by indicating the probability of particular outputs, it would allow making more insightful decisions regarding further funding and development of the calcium looping process. Furthermore, such an approach would allow considering the effect of the uncertainty in the external factors, such as fuel characteristics, marked energy demand, and ambient conditions, on the techno-economic feasibility of such low-carbon power generation systems. In turn, this would allow drawing more accurate conclusions on the process feasibility and operability under uncertain conditions within the entire energy network. Such analysis was, however, out of this study scope.

Finally, employing the stochastic analysis in the techno-economic feasibility assessment allows undertaking a more profound comparison across the different process configurations as well as benchmarking the calcium looping process against other $\mathrm{CO}_{2}$ capture technologies. Such analysis would allow drawing more realistic 
conclusions, as inclusion of the uncertainty in the analysis yields the probability of the particular outputs.

\section{CONCLUSIONS}

This study employed the stochastic approach, which considers the effect of uncertainty on the predictions of the process and economic models, to assess the economic feasibility of the calcium looping retrofit to the $580 \mathrm{MW}_{\text {el }}$ supercritical coal-fired power plant. The stochastic economic analysis revealed that the key economic performance indicators, such as the LCOE and specific total capital requirement, are highly affected by uncertainty in the input variables to the process and economic models. The stochastic analysis revealed that the LCOE for the calcium looping process retrofit were nearly normally distributed with a slightly elongated region of the highest probability density. The most probable values of this key economic performance indicator fell between 75 and $115 € / \mathrm{MW}_{\text {elh}}$, respectively. Importantly, the most probable values of the LCOE for the reference coal-fired power plant were shown to be between 50 and $150 € / \mathrm{MW}_{\text {elh }}$, and this parameter was found to be strongly affected by the carbon tax. Conversely, the specific total capital requirement for the calcium looping retrofit scenario was shown to have a slightly positively-skewed normal distribution, and its most probable values were shown to fall between 2100 and 2300 $€ / \mathrm{kWel}$, gross.

The sensitivity analysis performed on the key statistic parameters of the selected stochastic variables revealed that the LCOE is mostly sensitive to the capacity factor, $\mathrm{CO}_{2}$ capture level in the carbonator, $\mathrm{O}_{2}$ content in the calciner inlet gas stream, project discount rate, coal price, scaling factor for the heat rate in the calciner, as well as the reference specific capital cost of both calcium looping and the reference coal-fired power plant. The specific total capital requirement was found to be sensitive mostly to 
$\mathrm{CO}_{2}$ capture level in the carbonator, $\mathrm{O}_{2}$ content in the calciner inlet gas stream, scaling factor for the heat rate in the calciner, as well as the reference specific capital cost of both calcium looping and the reference coal-fired power plant. Such outputs allowed ranking the stochastic input variables according to their influence on the key economic performance indicators.

A comparison between the deterministic data and the outputs of the stochastic economic analysis indicated that most of the results reported so far in the literature can be classified as the best- or probable-case scenarios that correspond to the $5^{\text {th }}$ or $50^{\text {th }}$ percentile of the key economic performance indicators, respectively. A limited number of studies was classified as the worst-case scenario (95 $5^{\text {th }}$ percentile), which was associated to a high estimate of the specific total capital requirement, the probability of which was estimated to be lower than $0.2 \%$. This had influenced the deterministic estimation of the LCOE, which was, therefore, classified as worst-case scenario. This was a result of this key economic performance indicator being sensitive to the reference specific capital cost of both calcium looping and coal-fired power plant. Nevertheless, as the outputs of the stochastic economic assessment align well with the deterministic results reported in the literature, which were generated using different sets of assumptions regarding the process and economic models, such approach to the economic assessment can alleviate the impact of the model assumptions on the economic estimates. Moreover, by indicating the probability of particular outputs, it would allow making more insightful decisions regarding further funding and development of the calcium looping process. Furthermore, use of the stochastic approach in the economic feasibility assessment enables a more profound and reliable comparison of the different calcium looping retrofit configurations, as well as benchmarking different $\mathrm{CO}_{2}$ capture technologies. 


\section{REFERENCES}

[1] UN. Adoption of the Paris Agreement. Paris, France: United Nations Framework Convenction on Climate Change; 2015.

[2] IEA. Technology Roadmap: Carbon capture and storage. Paris, France: IEA Publications; 2013.

[3] IEA. $\mathrm{CO}_{2}$ Emissions from Fuel Combustion - Highlights. Paris, France: IEA Publications; 2012.

[4] Yu S, Wei YM, Guo H, Ding L. Carbon emission coefficient measurement of the coal-to-power energy chain in China. Appl Energy 2014;114:290-300. doi:10.1016/j.apenergy.2013.09.062.

[5] Karampinis E, Nikolopoulos N, Nikolopoulos A, Grammelis P, Kakaras E. Numerical investigation Greek lignite/cardoon co-firing in a tangentially fired furnace. Appl Energy 2012;97:514-24. doi: 10.1016/j.apenergy.2011.12.032.

[6] Orion Innovations. A UK Vision for Carbon Capture and Storage. London, UK: 2013.

[7] Abdul Manaf N, Qadir A, Abbas A. Temporal multiscalar decision support framework for flexible operation of carbon capture plants targeting low-carbon management of power plant emissions. Appl Energy 2016;169:912-26. doi:10.1016/j.apenergy.2016.02.052.

[8] Rackley SA. Carbon Capture and Storage. Burlington, USA: Elsevier; 2010.

[9] Blamey J, Anthony EJ, Wang J, Fennell PS. The calcium looping cycle for largescale $\mathrm{CO}_{2}$ capture. Prog Energy Combust Sci 2010;36:260-79. doi:10.1016/j.pecs.2009.10.001.

[10] Boot-Handford ME, Abanades JC, Anthony EJ, Blunt MJ, Brandani S, Mac Dowell N, et al. Carbon capture and storage update. Energy Environ Sci 2014;7:130-89. doi:10.1039/C3EE42350F.

[11] Pires JCM, Martins FG, Alvim-Ferraz MCM, Simões M. Recent developments on carbon capture and storage: An overview. Chem Eng Res Des 2011;89:1446-60. doi:10.1016/j.cherd.2011.01.028.

[12] Liang Z, Rongwong W, Liu H, Fu K, Gao H, Cao F, et al. Recent progress and new developments in post-combustion carbon-capture technology with amine based solvents. Int $J$ Greenh Gas Control 2015;40:26-54. doi:10.1016/j.ijggc.2015.06.017.

[13] Hanak DP, Anthony EJ, Manovic V. A review of developments in pilot plant testing and modelling of calcium looping process for $\mathrm{CO}_{2}$ capture from power generation systems. Energy Environ Sci 2015;8:2199-2249. doi:10.1039/C5EE01228G.

[14] Hanak DP, Biliyok C, Manovic V. Evaluation and modeling of part-load performance of coal-fired power plant with postcombustion $\mathrm{CO}_{2}$ capture. Energy and Fuels 2015;29:3833-44. doi:10.1021/acs.energyfuels.5b00591.

[15] Abanades JC, Arias B, Lyngfelt A, Mattisson T, Wiley DE, Li H, et al. Emerging $\mathrm{CO}_{2}$ capture systems. Int J Greenh Gas Control 2015;40:126-66. 
doi:10.1016/j.jjggc.2015.04.018.

[16] Perejón A, Romeo LM, Lara Y, Lisbona P, Martínez A, Valverde JM. The Calcium-Looping technology for $\mathrm{CO}_{2}$ capture: On the important roles of energy integration and sorbent behavior. Appl Energy 2016;162:787-807. doi:10.1016/j.apenergy.2015.10.121.

[17] Romano MC, Spinelli M, Campanari S, Consonni S, Cinti G, Marchi M, et al. The calcium looping process for low $\mathrm{CO}_{2}$ emission cement and power. Energy Procedia 2013;37:7091-9. doi:10.1016/j.egypro.2013.06.645.

[18] Romeo LM, Abanades JC, Escosa JM, Paño J, Giménez A, Sánchez-Biezma A, et al. Oxyfuel carbonation/calcination cycle for low cost $\mathrm{CO}_{2}$ capture in existing power plants. Energy Convers Manag 2008;49:2809-14. doi:10.1016/j.enconman.2008.03.022.

[19] Abanades JC, Grasa G, Alonso M, Rodriguez N, Anthony EJ, Romeo LM. Cost structure of a postcombustion $\mathrm{CO}_{2}$ capture system using $\mathrm{CaO}$. Environ Sci Technol 2007;41:5523-7. doi:10.1021/es070099a.

[20] Yang Y, Zhai R, Duan L, Kavosh M, Patchigolla K, Oakey J. Integration and evaluation of a power plant with a $\mathrm{CaO}$-based $\mathrm{CO}_{2}$ capture system. Int $\mathrm{J}$ Greenh Gas Control 2010;4:603-12. doi:10.1016/j.jiggc.2010.01.004.

[21] Hanak DP, Biliyok C, Manovic V. Calcium looping with inherent energy storage for decarbonisation of coal-fired power plant. Energy Environ Sci 2016;9:97183. doi:10.1039/C5EE02950C.

[22] Cormos C-C. Economic evaluations of coal-based combustion and gasification power plants with post-combustion $\mathrm{CO}_{2}$ capture using calcium looping cycle. Energy 2014;78:665-73. doi:10.1016/j.energy.2014.10.054.

[23] Mantripragada $\mathrm{HC}$, Rubin ES. Calcium looping cycle for $\mathrm{CO}_{2}$ capture - Performance, cost and feasibility analysis. Energy Procedia 2013;63:2199206.

[24] ZEP. The costs of $\mathrm{CO}_{2}$ capture, transport and storage. European Technology Platform for Zero Emission Fossil Fuel Power Plants; 2011.

[25] Versteeg P, Rubin ES. A technical and economic assessment of ammoniabased post-combustion $\mathrm{CO}_{2}$ capture at coal-fired power plants. Int J Greenh Gas Control 2011;5:1596-605. doi:10.1016/j.ijggc.2011.09.006.

[26] Mac Dowell N, Shah N. The multi-period optimisation of an amine-based $\mathrm{CO}_{2}$ capture process integrated with a super-critical coal-fired power station for flexible operation. Comput Chem Eng 2015;74:169-83. doi:10.1016/j.compchemeng.2015.01.006.

[27] Rubin ES, Davison JE, Herzog HJ. The cost of $\mathrm{CO}_{2}$ capture and storage. Int J Greenh Gas Control 2015;40:378-400. doi:10.1016/j.ijggc.2015.05.018.

[28] Tzimas E. The cost of carbon capture and storage demonstration projects in Europe. Luxemburg: Publications Office of the European Union; 2009.

[29] Osmundsen P, Emhjellen M. CCS from the gas-fired power station at Karstø? A commercial analysis. Energy Policy 2010;38:7818-26. doi:10.1016/j.enpol.2010.08.041. 
[30] MIT. Kemper County IGCC Fact Sheet: Carbon Dioxide Capture and Storage Project. Cambridge, MA, USA: Massachusetts Institute of Technology; 2016.

[31] MIT. Boundary Dam Fact Sheet: Carbon Dioxide Capture and Storage Project. Cambridge, MA, USA: Massachusetts Institute of Technology; 2016.

[32] Rubin ES, Kalagnanam JR, Frey HC, Berkenpas MB. Integrated environmental control modeling of coal-fired power systems. J Air Waste Manag Assoc 1997;47:1180-8.

[33] Rubin ES, Rao AB. Uncertainties in $\mathrm{CO}_{2}$ capture and sequestration costs. In: Kaya JG, editor. Greenh. Gas Control Technol. $6^{\text {th }}$ Int. Conf., Oxford: Pergamon; 2003, 1119-24. doi:10.1016/B978-008044276-1/50177-X.

[34] Frey HC, Rubin ES. Probabilistic evaluation of advanced $\mathrm{SO}_{2} / \mathrm{NO}_{x}$ control technology. J Air Waste Manag Assoc 1991;41:1585-93.

[35] Hanak DP, Kolios AJ, Biliyok C, Manovic V. Probabilistic performance assessment of a coal-fired power plant. Appl Energy 2015;139:350-64. doi:10.1016/j.apenergy.2014.10.079.

[36] Hanak DP, Kolios AJ, Manovic V. Comparison of probabilistic performance of calcium looping and chemical solvent scrubbing retrofits for $\mathrm{CO}_{2}$ capture from coal-fired power plant. Appl Energy 2016;172:323-36. doi:10.1016/j.apenergy.2016.03.102.

[37] Geissmann T. A probabilistic approach to the computation of the levelized cost of electricity. Energy 2017;124:372-81. doi:10.1016/j.energy.2017.02.078.

[38] Heck N, Smith C, Hittinger E. A Monte Carlo approach to integrating uncertainty into the levelized cost of electricity. Electr $J$ 2016;29:21-30. doi:10.1016/j.tej.2016.04.001.

[39] Hanak DP, Biliyok C, Manovic V. Efficiency improvements for the coal-fired power plant retrofit with $\mathrm{CO}_{2}$ capture plant using chilled ammonia process. Appl Energy 2015;151:258-72. doi:10.1016/j.apenergy.2015.04.059.

[40] Hanak DP, Biliyok C, Manovic V. Rate-based model development, validation and analysis of chilled ammonia process as an alternative $\mathrm{CO}_{2}$ capture technology for coal-fired power plants. Int J Greenh Gas Control 2015;34:5262. doi:10.1016/j.ijggc.2014.12.013.

[41] Black J. Cost and performance baseline for fossil energy plants volume 1: Bituminous coal and natural gas to electricity. DOE/2010/1. National Energy Technology Laboratory; 2013.

[42] Hanak DP, Biliyok C, Anthony EJ, Manovic V. Modelling and comparison of calcium looping and chemical solvent scrubbing retrofits for $\mathrm{CO}_{2}$ capture from coal-fired power plant. Int J Greenh Gas Control 2015;42:226-36. doi:10.1016/j.jjggc.2015.08.003.

[43] Rodríguez N, Alonso M, Abanades JC. Average activity of $\mathrm{CaO}$ particles in a calcium looping system. Chem Eng J 2010;156:388-94. doi:http://dx.doi.org/10.1016/j.cej.2009.10.055.

[44] Sánchez-Biezma A, Paniagua J, Diaz L, Lorenzo M, Alvarez J, Martínez D, et al. Testing postcombustion $\mathrm{CO}_{2}$ capture with $\mathrm{CaO}$ in a $1.7 \mathrm{MW}$ pilot facility. 
Energy Procedia 2013;37:1-8. doi:10.1016/j.egypro.2013.05.078.

[45] Baker $\mathrm{EH}$. The calcium oxide-carbon dioxide system in the pressure range 1300 atmospheres. J Chem Soc 1962:464-70.

[46] Zhao M, Minett Al, Harris AT. A review of techno-economic models for the retrofitting of conventional pulverised-coal power plants for post-combustion capture (PCC) of $\mathrm{CO}_{2}$. Energy Environ Sci 2013;6:25-40. doi:10.1039/c2ee22890d.

[47] Perry RH, Green DW, Maloney JO. Perry's Chemical Engineers' Handbook. $7^{\text {th }}$ edition. New York: McGraw-Hill; 2007.

[48] Marion J, Nsakala N, McWhinnie R. Greenhouse gas emissions control by oxygen firing in circulating fluidized bed boilers: Phase 1-A preliminary systems evaluation. 2003.

[49] $\mathrm{Hu} \mathrm{M}$, Cho H. A probability constrained multi-objective optimization model for CCHP system operation decision support. Appl Energy 2014;116:230-42. doi: 10.1016/j.apenergy.2013.11.065.

[50] Berstad D, Anantharaman R, Jordal K. Post-combustion $\mathrm{CO}_{2}$ capture from a natural gas combined cycle by $\mathrm{CaO} / \mathrm{CaCO}_{3}$ looping. Int J Greenh Gas Control 2012;11:25-33. doi:10.1016/j.ijggc.2012.07.021.

[51] Lasheras A, Ströhle J, Galloy A, Epple B. Carbonate looping process simulation using a 1D fluidized bed model for the carbonator. Int J Greenh Gas Control 2011;5:686-93. doi:10.1016/j.jjggc.2011.01.005.

[52] Martínez I, Murillo R, Grasa G, Carlos Abanades J. Integration of a Ca looping system for $\mathrm{CO}_{2}$ capture in existing power plants. AIChE J 2011;57:2599-607. doi:10.1002/aic.12461.

[53] Charitos A, Rodríguez N, Hawthorne C, Alonso M, Zieba M, Arias B, et al. Experimental validation of the calcium looping $\mathrm{CO}_{2}$ capture process with two circulating fluidized bed carbonator reactors. Ind Eng Chem Res 2011;50:968595. doi:10.1021/ie200579f.

[54] Rodríguez N, Alonso M, Abanades JC. Experimental investigation of a circulating fluidized-bed reactor to capture $\mathrm{CO}_{2}$ with $\mathrm{CaO}$. AlChE $\mathrm{J}$ 2011;57:1356-66. doi:10.1002/aic.12337.

[55] Yang WC. Handbook of fluidization and fluid-particle systems. 2003. doi:10.1016/S1672-2515(07)60126-2.

[56] Romano MC. Modeling the carbonator of a Ca-looping process for $\mathrm{CO}_{2}$ capture from power plant flue gas. Chem Eng Sci 2012;69:257-69. doi:10.1016/j.ces.2011.10.041.

[57] DECC. Updated energy and emissions projections 2014. London, UK: Department of Energy and Climate Change; 2014.

[58] EIA. Energy market and economic impacts of the American Power Act of 2010. Washington, DC, USA: U.S. Energy Information Administration; 2010.

[59] Mendelevitch $\mathrm{R}$. The role of $\mathrm{CO}_{2}$-EOR for the development of a CCTS infrastructure in the North Sea Region. Int J Greenh Gas Control 2014;20:132- 
59. doi:10.1016/j.ijggc.2013.11.007.

[60] GCCSI. Accelerating the uptake of CCS: industrial use of captured carbon dioxide. Docklands, Australia: Global Carbon Capture and Storage Institute, Parsons Brinckerhoff; 2011.

[61] Choi SK, Grandhi R V, Canfield RA. Reliability-based structural design. London, UK: Springer-Verlag; 2007.

[62] Oko E, Wang M, Zhang J. Neural network approach for predicting drum pressure and level in coal-fired subcritical power plant. Fuel 2015;151:139-45. doi:10.1016/j.fuel.2015.01.091.

[63] Kalogirou SA. Applications of artificial neural-networks for energy systems. Appl Energy 2000;67:17-35. doi:10.1016/S0306-2619(00)00005-2.

[64] Smrekar J, Assadi M, Fast M, Kuštrin I, De S. Development of artificial neural network model for a coal-fired boiler using real plant data. Energy 2009;34:14452. doi:10.1016/j.energy.2008.10.010.

[65] Boukelia TE, Arslan O, Mecibah MS. Potential assessment of a parabolic trough solar thermal power plant considering hourly analysis: ANN-based approach. Renew Energy 2017;105:324-33. doi:10.1016/j.renene.2016.12.081. 


\section{NOMENCLATURE}

$a$

$a_{1}$

$a_{2}$

$b$

$b_{i}$

$C_{0}$

CF

$c_{i}$

$e_{\mathrm{CO}_{2}}$

EP

$f$

$F_{0}$

$f_{1}$

$f_{2}$

$f_{\text {calc }}$

$f_{\text {carb }}$

FCF

FOM

$F_{R}$

$\tilde{g}$

LCOE

$\dot{\mathrm{m}}_{\mathrm{CO}_{2}}$

$S C F$

$S F, Q$

$S F, V$

TCR

$Q_{0, \text { calc }}$

$Q_{\text {calc }}$

$r_{0}$

V

$V_{0}$

VOM

$u_{i}$

$w_{k}$

$\dot{W}_{\text {net }}$

$X_{\text {ave }}$

$y$

$\alpha$

$\eta_{t h}$

$\eta_{b}$

$\theta$

$\varphi$

Multi-variable polynomial parameter

Li et al. [33] model fitting parameter

Li et al. [33] model fitting parameter

Li et al. [33] model fitting parameter

Multi-variable polynomial parameter

Reference capital cost of calcium looping process

$€ / k W_{\text {el }}$

Capacity factor

Multi-variable polynomial parameter

Specific $\mathrm{CO}_{2}$ emission

Net efficiency penalty

Neuron activation function

Fresh-limestone make up rate

Li et al. [33] model fitting parameter

Li et al. [33] model fitting parameter

Calcination reaction extent

Carbonation reaction extent

Fixed charge factor

Fixed operating and maintenance cost

$\mathrm{CaO}$ looping rate

Dependent variable

Levelised cost of electricity

Rate of $\mathrm{CO}_{2}$ emission

Specific fuel cost

Scaling factor for reactor heat input

Scaling factor for reactor volume

Total capital requirement

$\mathrm{gCO}_{2} / \mathrm{kW}_{\text {elh }}$

$\%$ HHV points

$\mathrm{kmol} / \mathrm{s}$

Reference heat input to the calciner

Heat input to the calciner

Fraction of never calcined limestone in the system

Volume of reactors

Reference volume of reactor

$\mathrm{kmol} / \mathrm{s}$

Variable operating and maintenance cost

Stochastic variable

Artificial neural network node weight

Net power output of the integrated system

Average sorbent conversion

Artificial neural network output

Fraction of the total cost of a circulating fluidised bed reactor associated with the heat transfer surfaces

Net thermal efficiency

Boiler thermal efficiency

Artificial neural network layer bias

Neuron output 


\section{ABBREVIATIONS}

$\begin{array}{ll}\text { ANN } & \text { Artificial neural network } \\ \text { CCS } & \text { Carbon capture and storage } \\ \text { CCU } & \mathrm{CO}_{2} \text { compression unit } \\ \text { HP } & \text { High-pressure } \\ \text { IP } & \text { Intermediate-pressure } \\ \text { LCOE } & \text { Levelised cost of electricity } \\ \text { LP } & \text { Low-pressure } \\ \text { MEA } & \text { Monoethanolamine } \\ \text { MDEA } & \text { Methyldiethanolamine } \\ \text { MVR } & \text { Multi-variable polynomial } \\ \text { PZ } & \text { Piperazine }\end{array}$

